\title{
Comparison of gall bladder bile and endoscopically obtained duodenal bile
}

\author{
P Janowitz, W Swobodnik, J G Wechsler, A Zöller, K Kuhn, H Ditschuneit
}

\begin{abstract}
In 10 patients with gall stone disease (eight women, two men; mean (SD) age 47.4 (13) years), bile was obtained by endoscopic aspiration after stimulation of the gall bladder with ceruletid and also by fine needle puncture of the gall bladder under local anaesthetic. The total lipid concentration of the puncture bile samples was mean (SD) 11.9 (4.7) g/dl, significantly higher than the endoscopic bile samples (3.9 (3.3) $\mathrm{g} / \mathrm{dl}, \mathrm{p}<0.001)$. Total bile acids, phospholipids, and biliary cholesterol (expressed in mol\%) and cholesterol saturation index showed no significant differences between the two types of samples. The glycocholic acid concentration in the endoscopically obtained bile $(27 \cdot 7(6 \cdot 6) \mathrm{mol} \% v 23.3(5 \cdot 4)$ mol\%; $p<0.01)$ was significantly higher than the puncture bile samples. Puncture bile exhibited a significantly shorter nucleation time (3.5 (3.3) days $v 19.6$ (11.9) days; $\mathrm{p}<\mathbf{0 . 0 0 1 )}$. For determination of the nucleation time, endoscopic bile aspiration after gall bladder stimulation with ceruletid led to adequately concentrated samples in $\mathbf{5 0 \%}$ of the study subjects. Cholesterol monohydrate crystal formation in native bile was observed in six samples of puncture bile and in three samples of the endoscopically obtained bile. The presence of cholesterol crystals and the determination of nucleation time in the puncture bile were the best discriminants between cholesterol and pigment gall stones and correlated well with computed tomogram analysis.
\end{abstract}

Progress in the conservative treatment of gall stone disease (oral dissolution therapy, percutaneous lysis, extracorporeal shock waves) has focused attention on the importance of adequate patient selection methods. ${ }^{1-4}$ Gall stones are best classified in vivo by determining their density (expressed in terms of Hounsfield units, HU) using computed tomography or by appropriate

Department of Internal

Medicine II and

Radiology, University

Clinic Ulm,

West Germany

P Janowitz

W Swobodnik

J G Wechsler

A Zöller

K Kuhn

H Ditschuneit

Correspondence to:

Dr P Janowitz, Department of

Internal Medicine II,

University Clinic Ulm

Robert-Koch-Strasse 8,

7900 Ulm, West Germany.

Accepted for publication

12 February 1990 bile analysis (nucleation time, cholesterol monohydrate crystal occurrence, and, possibly, the cholesterol saturation index). ${ }^{5-7}$ Patients with bilirubin stones show a stone density of $>50 \mathrm{HU}$ and a significantly longer nucleation time, in addition to the absence of monohydrate crystals in native bile. ${ }^{58}$ The presence of cholesterol crystals is significantly related to the cholesterol content of gall stones. ${ }^{9}$ A nucleation time of less than eight days in duodenal bile samples augurs well for the success of oral dissolution treatment. ${ }^{10}$ In previous studies, it has only been possible to obtain gall bladder bile during cholecystectomy. Duodenal bile is diluted with gastric, pancreatic, and intestinal secretions which inevitably contaminate it.

We present the results of our investigation into the suitability of endoscopically obtained bile and bile obtained by fine needle puncture of the gall bladder for purposes of measuring bile nucleation time, cholesterol saturation index, the occurrence of cholesterol monohydrate crystals, and the lipid content.

\section{Patients and methods}

Ten patients with radiolucent gall stones (eight women, two men; mean (SD) age 47.4 (13) years; weight $68 \cdot 6(7 \cdot 8) \mathrm{kg}$ ) were included in our study. Computed tomography of the gall bladder was used as the gold standard technique for classification of gall stone type. Five of the study subjects suffered from bilirubin stones or from partially calcified stones visible only by computed tomography (density $>50 \mathrm{HU}$ ) (see Table I). The remaining five patients showed stone densities of $<30 \mathrm{HU}$ and were placed in the cholesterol stone category.

All patients exhibited adequate gall bladder contractility and no contraindications to oral dissolution treatment were identified in any.

Bile was obtained by fine needle puncture of the gall bladder under ultrasound control. After skin disinfection and local anaesthesia of the puncture site and track with $10 \mathrm{ml}$ mepivacain (Meaverin), aseptic transhepatic puncture of the gall bladder in the supine patient was carried out through the gall bladder bed in the upper right quadrant. The fine needle $(23 \mathrm{G}, 9 \mathrm{~cm})$ was introduced under continuous ultrasound monitoring (ATL, Ultramark 9, $5 \mathrm{MHz}$ annular array) until the tip had reached the centre of the gall bladder body. Complete aspiration of the total gall bladder contents followed. In no case was a repetition of the procedure required. All patients were monitored for 24 hours in the ward after the procedure.

Gastroscopy and endoscopic bile aspiration were carried out one to seven days (mean (SD) $2 \cdot 4(1 \cdot 7)$ days) after puncture. The gall bladder 
was stimulated with $2 \cdot 5-7 \cdot 5 \mu \mathrm{g}$ ceruletid (Takus) given intravenously, and prepapillary bile aspiration was carried out under visual control via a cannula introduced through the biopsy channel.

Only the darkest bile samples were subsequently analysed. In each patient bile was obtained between 8.00 and 9.00 am, after 12 hours fasting. None of the subjects received medication that influences biliary lipid values.

In addition, gastroscopy allowed the exclusion of occult peptic ulcer disease, which is thought to be a contraindication for bile acid treatment of gall stones.

The bile samples were ultracentrifuged for two hours at $100000 \mathrm{~g}\left(37^{\circ} \mathrm{C}\right)$ and the resulting isotropic (cholesterol and liquid crystal free) phase was incubated at $37^{\circ} \mathrm{C}$ under sterile conditions. The sediment was also examined for solid cholesterol monohydrate crystals. The nucleation time was determined using the method of Holan et al, defined as the time of earliest appearance (expressed in days) of cholesterol monohydrate crystals in aliquots of the incubated isotropic bile phase.

Bile acid analysis was carried out using high pressure liquid chromatography with dexamethasone as the internal standard. ${ }^{11}$ The cholesterol concentration was measured enzymatically (Chod-Pap method, enzymatic colour test, Boehringer Mannheim, FRG), as was the phospholipid concentration (enzymatic colour test, Boehringer Mannheim, FRG). The total lipid concentration as a measure of bile dilution derives from the individual bile acid, phospholipid, and cholesterol concentrations and was expressed in $\mathrm{g} / \mathrm{dl}$ (cholesterol $386 \mathrm{~g} / \mathrm{mol}$, bile acids $495 \mathrm{~g} / \mathrm{mol}$, lecithin $735 \mathrm{~g} / \mathrm{mol}$ ). The cholesterol saturation index was determined using the method of Admirand and Small, without the correction after Carey. ${ }^{1213}$

All data are presented as mean (SD). Statistical significance was calculated using the Student's $t$ test for dependent random samples $(\mathrm{p}<0.05)$.

The direct fine needle puncture of gall stone patients under continuous ultrasound monitoring was approved by the ethics committee of the University of Ulm.

\section{Results}

The bile obtained endoscopically was more dilute as judged by its significantly lower total lipid concentrations (mean (SD) 3.9 (3.3) g/dl (range: $0 \cdot 15-8.64 \mathrm{~g} / \mathrm{dl}) v 11.9(4 \cdot 7) \mathrm{g} / \mathrm{dl}$ (range: $4.42-21.36 \mathrm{~g} / \mathrm{dl})(\mathrm{p}<0.001)$ (see Tables II and III). There was no significant correlation between the total lipid concentrations of the bile obtained endoscopically and those obtained through fine needle puncture $(r=0.55 ; \mathrm{NS})$.

In two instances the endoscopic bile was so dilute that determination of the cholesterol saturation index was impossible. The saturation index of the puncture bile $(1 \cdot 17(0 \cdot 26)$; range: $0.55-1.64)$ tended to be lower than that of the endoscopic bile (1.84 (0.84); range: $1 \cdot 07-3 \cdot 29)$, though the differences are not statistically significant.

Compared in terms of mol\%, there was no statistically significant difference between concentrations of bile acids, phospholipids, and cholesterol in endoscopic bile and puncture bile.

All patients who were believed to have choles-

TABLE II Summary of gall bladder bile sample analyses

\begin{tabular}{|c|c|c|c|c|c|c|c|c|c|c|c|c|}
\hline \multirow[b]{2}{*}{ Patient } & \multirow[b]{2}{*}{ Sex } & \multirow[b]{2}{*}{ Age } & \multicolumn{2}{|l|}{ Bile acids } & \multicolumn{2}{|c|}{ Phospholipids } & \multicolumn{2}{|c|}{ Cholesterol } & \multirow{2}{*}{$\begin{array}{l}T L C \\
(g / d l)\end{array}$} & \multirow[b]{2}{*}{$C S I$} & \multirow{2}{*}{$\begin{array}{l}N T \\
\text { (days) }\end{array}$} & \multirow[b]{2}{*}{ CMH } \\
\hline & & & $(\mathrm{mmol} / \mathrm{l})$ & $(m o l \%)$ & $(\mathrm{mmol} / \mathrm{l})$ & $(m o l \%)$ & $(\mathrm{mmol} / \mathrm{l})$ & $(m o l \%)$ & & & & \\
\hline $\begin{array}{r}1 \\
2 \\
3 \\
4 \\
5 \\
6 \\
7 \\
8 \\
9 \\
10\end{array}$ & $\begin{array}{l}F \\
M \\
F \\
F \\
F \\
F \\
M \\
F \\
F \\
F\end{array}$ & $\begin{array}{l}67 \\
60 \\
37 \\
39 \\
42 \\
45 \\
68 \\
43 \\
30 \\
43\end{array}$ & $\begin{array}{r}136 \cdot 56 \\
148 \cdot 27 \\
205 \cdot 42 \\
272 \cdot 27 \\
273 \cdot 21 \\
104 \cdot 28 \\
55 \cdot 50 \\
139 \cdot 80 \\
153 \cdot 15 \\
209 \cdot 77\end{array}$ & $\begin{array}{l}78 \cdot 47 \\
79 \cdot 42 \\
81 \cdot 60 \\
83 \cdot 26 \\
69 \cdot 07 \\
67 \cdot 59 \\
68 \cdot 31 \\
71 \cdot 09 \\
75 \cdot 32 \\
75 \cdot 75\end{array}$ & $\begin{array}{l}31 \cdot 91 \\
27 \cdot 42 \\
32 \cdot 36 \\
37 \cdot 32 \\
89 \cdot 04 \\
32 \cdot 84 \\
19 \cdot 45 \\
41 \cdot 12 \\
35 \cdot 26 \\
47 \cdot 97\end{array}$ & $\begin{array}{l}18 \cdot 33 \\
14.68 \\
12 \cdot 85 \\
11 \cdot 41 \\
22.50 \\
21 \cdot 28 \\
23.94 \\
20.91 \\
17 \cdot 34 \\
17 \cdot 32\end{array}$ & $\begin{array}{r}5.54 \\
11.00 \\
13.95 \\
17 \cdot 40 \\
33.44 \\
17 \cdot 16 \\
6.29 \\
15 \cdot 73 \\
14.90 \\
19 \cdot 18\end{array}$ & $\begin{array}{r}3 \cdot 18 \\
5 \cdot 89 \\
5 \cdot 54 \\
5 \cdot 32 \\
8 \cdot 45 \\
11 \cdot 12 \\
7 \cdot 74 \\
7 \cdot 99 \\
7 \cdot 33 \\
6.92\end{array}$ & $\begin{array}{r}9 \cdot 31 \\
9.78 \\
13.08 \\
16.89 \\
21.36 \\
8.23 \\
4 \cdot 42 \\
10.55 \\
10.74 \\
14.65\end{array}$ & $\begin{array}{l}0.55 \\
1.10 \\
1.19 \\
1.22 \\
1.23 \\
1.64 \\
1.09 \\
1.22 \\
1.29 \\
1.21\end{array}$ & $\begin{array}{r}10 \\
7 \\
1 \\
1 \\
1 \\
1 \\
6 \\
5 \\
1 \\
2\end{array}$ & $\begin{array}{l}- \\
- \\
+++ \\
+++ \\
+ \\
+++ \\
- \\
- \\
+ \\
+\end{array}$ \\
\hline $\begin{array}{l}\text { Mean } \\
\text { (SD) }\end{array}$ & & $\begin{array}{c}47 \cdot 4 \\
(13 \cdot 0)\end{array}$ & $\begin{array}{l}169 \cdot 82 \\
(70 \cdot 05)\end{array}$ & $\begin{array}{l}74 \cdot 98 \\
(5 \cdot 71)\end{array}$ & $\begin{array}{c}39 \cdot 47 \\
(19 \cdot 00)\end{array}$ & $\begin{array}{l}18 \cdot 06 \\
(4 \cdot 17)\end{array}$ & $\begin{array}{l}15 \cdot 46 \\
(7 \cdot 80)\end{array}$ & $\begin{array}{c}6 \cdot 98 \\
(2 \cdot 14)\end{array}$ & $\begin{array}{l}11 \cdot 90 \\
(4 \cdot 79)\end{array}$ & $\begin{array}{c}1 \cdot 17 \\
(0 \cdot 26)\end{array}$ & $\begin{array}{c}3 \cdot 5 \\
(3 \cdot 3)\end{array}$ & \\
\hline
\end{tabular}

$\mathrm{TLC}=$ total lipid concentration $; \mathrm{CSI}=$ cholesterol saturation index $\mathrm{NT}=$ nucleation time $\mathbf{C M H}=$ cholesterol monohydrate crystals

TABLE III Summary of duodenal bile sample analyses

\begin{tabular}{|c|c|c|c|c|c|c|c|c|c|c|c|c|}
\hline \multirow[b]{2}{*}{ Patient } & \multirow[b]{2}{*}{ Sex } & \multirow[b]{2}{*}{ Age } & \multicolumn{2}{|l|}{ Bile acids } & \multicolumn{2}{|c|}{ Phospholipids } & \multicolumn{2}{|c|}{ Cholesterol } & \multirow{2}{*}{$\begin{array}{l}T L C \\
(g / d l)\end{array}$} & \multirow[b]{2}{*}{$C S I$} & \multirow{2}{*}{$\begin{array}{l}N T \\
\text { (days) }\end{array}$} & \multirow[b]{2}{*}{$\mathrm{CMH}$} \\
\hline & & & $(\mathrm{mmol} / \mathrm{l})$ & $(\mathrm{mol} \%)$ & $(\mathrm{mmol} / \mathrm{l})$ & $(\mathrm{mol} \%)$ & $(\mathrm{mmol} / \mathrm{l})$ & $(\mathrm{mol} \%)$ & & & & \\
\hline $\begin{array}{r}1 \\
2 \\
3 \\
4 \\
5 \\
6 \\
7 \\
8 \\
9 \\
10\end{array}$ & $\begin{array}{l}F \\
M \\
F \\
F \\
F \\
F \\
M \\
F \\
F \\
F\end{array}$ & $\begin{array}{l}67 \\
60 \\
37 \\
39 \\
42 \\
45 \\
68 \\
43 \\
30 \\
43\end{array}$ & $\begin{array}{r}9.63 \\
126.30 \\
115 \cdot 26 \\
100 \cdot 26 \\
82.55 \\
2.66 \\
28.31 \\
21.24 \\
1.31 \\
81.83\end{array}$ & $\begin{array}{l}89 \cdot 58 \\
77 \cdot 26 \\
77 \cdot 55 \\
80 \cdot 65 \\
69 \cdot 79 \\
63 \cdot 63 \\
79 \cdot 12 \\
69 \cdot 36 \\
55 \cdot 74 \\
77 \cdot 16\end{array}$ & $\begin{array}{r}0 \cdot 12 \\
27.47 \\
23.08 \\
15.60 \\
25.02 \\
0.38 \\
2.88 \\
5 \cdot 76 \\
0.29 \\
16.44\end{array}$ & $\begin{array}{r}1 \cdot 11 \\
16 \cdot 80 \\
15 \cdot 53 \\
12.55 \\
21 \cdot 15 \\
9 \cdot 09 \\
8 \cdot 05 \\
18 \cdot 81 \\
12.32 \\
15.50\end{array}$ & $\begin{array}{r}1.00 \\
9 \cdot 70 \\
10 \cdot 28 \\
8 \cdot 45 \\
10 \cdot 70 \\
1 \cdot 14 \\
4.59 \\
3.62 \\
0.75 \\
7 \cdot 78\end{array}$ & $\begin{array}{c}9.30 \\
5.93 \\
6.91 \\
6 \cdot 79 \\
9.04 \\
27 \cdot 2 \\
12 \cdot 82 \\
11.82 \\
31.91 \\
7 \cdot 33\end{array}$ & $\begin{array}{l}0.52 \\
8.64 \\
7.79 \\
6.43 \\
6.34 \\
0.20 \\
1.79 \\
1.61 \\
0.15 \\
5.56\end{array}$ & $\begin{array}{l}3.01 \\
1 \cdot 06 \\
1 \cdot 31 \\
1.48 \\
1 \cdot 36 \\
\overline{3} \cdot 29 \\
1 \cdot 88 \\
\overline{1} \cdot 39\end{array}$ & $\begin{array}{r}>30 \\
>30 \\
5 \\
2 \\
12 \\
>30 \\
>30 \\
7 \\
>30 \\
20\end{array}$ & $\begin{array}{l}- \\
- \\
++ \\
+++ \\
+ \\
- \\
- \\
- \\
- \\
-\end{array}$ \\
\hline $\begin{array}{l}\text { Mean } \\
\text { (SD) }\end{array}$ & & $\begin{array}{c}47 \cdot 4 \\
(13 \cdot 0)\end{array}$ & $\begin{array}{c}56 \cdot 93 \\
(49 \cdot 14)\end{array}$ & $\begin{array}{l}73 \cdot 98 \\
(9 \cdot 58)\end{array}$ & $\begin{array}{c}11 \cdot 70 \\
(11.04)\end{array}$ & $\begin{array}{l}13.09 \\
(5.86)\end{array}$ & $\begin{array}{c}5 \cdot 80 \\
(4 \cdot 03)\end{array}$ & $\begin{array}{l}12 \cdot 91 \\
(9 \cdot 12)\end{array}$ & $\begin{array}{c}3.90 \\
(3.36)\end{array}$ & $\begin{array}{c}1 \cdot 84 \\
(0 \cdot 84)\end{array}$ & $\begin{array}{c}19 \cdot 6 \\
(11.9)\end{array}$ & \\
\hline
\end{tabular}

$\mathrm{TLC}=$ total lipid concentration $\mathrm{CSI}=$ cholesterol saturation index $\mathrm{NT}=$ nucleation time; $\mathrm{CMH}=$ cholesterol monohydrate crystals . 
TABLE IV Biliary bile acid patterns (values mean $(S D)$ )

\begin{tabular}{lll}
\hline & $\begin{array}{l}\text { Gall bladder } \\
\text { bile }(\text { mol } \%)\end{array}$ & $\begin{array}{l}\text { Duodenal } \\
\text { bile }(\text { mol } \%)\end{array}$ \\
\hline Cholic acid & $35 \cdot 3(8 \cdot 6)$ & $40 \cdot 4(8 \cdot 9)$ \\
Glycocholic acid & $23 \cdot 3(5 \cdot 4)^{\star}$ & $27 \cdot 7(6 \cdot 6)^{\star}$ \\
Taurocholic acid & $12 \cdot 0(5 \cdot 0)$ & $12 \cdot 6(5 \cdot 3)$ \\
Chenodeoxycholic acid & $38 \cdot 9(6 \cdot 9)$ & $37 \cdot 1(6 \cdot 8)$ \\
Glycochenodeoxycholic acid & $26 \cdot 6(5 \cdot 7)$ & $25 \cdot 7(4 \cdot 5)$ \\
Taurochenodeoxycholic acid & $12 \cdot 3(4 \cdot 7)$ & $11 \cdot 3(3 \cdot 9)$ \\
Deoxycholic acid & $22 \cdot 4(10 \cdot 3)$ & $19 \cdot 8(10 \cdot 6)$ \\
Glycodeoxycholic acid & $17 \cdot 2(8 \cdot 5)$ & $14 \cdot 7(8 \cdot 5)$ \\
Taurodeoxycholic acid & $5 \cdot 2(2 \cdot 3)$ & $5 \cdot 0(2 \cdot 4)$ \\
Lithocholic acid & $0 \cdot 6(0 \cdot 4)$ & $0 \cdot 6(0 \cdot 4)$ \\
Glycolithocholic acid & $0 \cdot 4(0 \cdot 3)$ & $0 \cdot 4(0 \cdot 3)$ \\
Taurolithocholic acid & $0 \cdot 2(0 \cdot 2)$ & $0 \cdot 3(0 \cdot 3)$ \\
Ursodeoxycholic acid & $2 \cdot 7(1 \cdot 3)$ & $2 \cdot 8(2 \cdot 4)$ \\
Glycoursodeoxycholic acid & $0 \cdot 9(0 \cdot 5)$ & $1 \cdot 7(1 \cdot 8)$ \\
Tauroursodeoxycholic acid & $1 \cdot 8(1 \cdot 2)$ & $2 \cdot 1(1 \cdot 0)$ \\
\hline n=10. & & \\
^p $<0 \cdot 01$. & &
\end{tabular}

terol stones on the basis of computed tomogram showed cholesterol monohydrate crystals in native puncture bile. One woman with a calcified cholesterol stone also showed monohydrate crystals in native bile. Conversely, in the endoscopically obtained samples, only three patients with cholesterol stones were found to have crystals in native bile.

The nucleation time, currently the best single parameter for the differentiation of cholesterol and bilirubin stones, was significantly shorter in the puncture bile $(3.5(3.39)$ days (range: 1.0 10.0 days)) than in the endoscopic samples $(19.6$ $(11 \cdot 9)$ days; range: $2 \cdot 0-30.0$ days; $\mathrm{p}<0 \cdot 001)$.

The glycocholic acid concentrations were significantly higher in the endoscopic bile $(27 \cdot 7$ mean (SD), (6.6) mol\%; range: $17 \cdot 8-40.9 \mathrm{~mol} \%$ ) than in the puncture bile $(23.3(5 \cdot 4) \mathrm{mol} \%$; range: $16.6-33.6 \mathrm{~mol} \% ; \mathrm{p}<0.01)$. We observed no other statistically significant differences in the concentrations of the other bile acids, including the total cholic acid concentration (see Table IV).

The puncture bile samples were also subjected to a bacteriological test. Bacterial contamination was found in two patients with bilirubin stones (Escherichia coli, E coli and Klebsiella species).

There were no complications reported in connection with the fine needle puncture. One woman complained of minor upper abdominal symptoms one day after the procedure. After intravenous administration of $2 \cdot 5 \mu \mathrm{g}$ ceruletid, one man experienced nausea and vomiting of such severity that an endoscopic examination had to be interrupted. This patient was not included in the study.

\section{Discussion}

Bile obtained endoscopically after stimulation of the normally functioning gall bladder with ceruletid proved to be sufficiently concentrated for evaluation of nucleation time in only $50 \%$ of patients. This was also reflected in the significantly lower total lipid concentrations in the endoscopically obtained samples $(3.9(3 \cdot 3) \mathrm{g} / \mathrm{dl} v$ $11.9(4.8) \mathrm{g} / \mathrm{dl} ; \mathrm{p}<0.001)$. In five instances, the total lipid concentrations lay between 5.56 and $8.64 \mathrm{~g} / \mathrm{dl}$, that is, sufficiently concentrated to permit determination of the nucleation time. Two samples, with total lipid concentrations of 1.61 and $1.79 \mathrm{~g} / \mathrm{dl}$ were well below the required concentration of $5 \mathrm{~g} / \mathrm{dl}$. In the remaining three, endoscopic bile aspiration was unsuccessful (total lipid concentrations between 0.15 and $0.52 \mathrm{~g} / \mathrm{dl}$ ).

The puncture bile samples of all five patients with cholesterol stones and of one woman with a calcified cholesterol stone showed cholesterol monohydrate crystals. The nucleation times of these samples lay between one and two days $(1 \cdot 1(0.4)$ days). The endoscopically obtained samples, however, showed cholesterol monohydrate crystals in only three samples from the five patients with cholesterol stones. The nucleation times varied between two and 12 days $(6 \cdot 3$ $(5 \cdot 1)$ days).

Nucleation times in the puncture bile of subjects with bilirubin stones were, as expected, longer - between five and 10 days $(7 \cdot 0(2 \cdot 1)$ days). The determination of the nucleation time in the endoscopic bile of these patients was not reliable, no nucleation having been observed even after 30 days.

The determination of total bile acids, phospholipids. biliary cholesterol (expressed in $\mathrm{mol} \%$ ), and cholesterol saturation index is reliable in endoscopically obtained bile.

The glycocholic acid concentrations in the endoscopically obtained bile samples were significantly higher than in the puncture bile $(27 \cdot 7$ (6.6) $\mathrm{mol} \%$ v $23.3(5.4) \mathrm{mol} \%$ ). We find no satisfactory explanation for this phenomenon.

The bile of two patients with bilirubin stones was contaminated with $E$ coli and with $E$ coli and Klebsiella species. This contamination offers a sufficient explanation for the formation of bilirubin stones. These patients are at high risk for the development of cholecystitis in the course of conservative dissolution therapy, particularly if local dissolution is attempted, ${ }^{214}$ and cholecystectomy is indicated in such cases.

Recent studies agree that cholesterol monohydrate crystal formation (nucleation time) is much more rapid in bile from patients with cholesterol gall stones, than in normal gall bladder bile or in bile from patients with pigment stones. ${ }^{7810}$ In patients with gall stones, cholesterol crystal occurrence helped to identify cholesterol gall stones (sensitivity $87 \%$, specificity $\mathbf{9 7 \%}$ ) better than an abnormal cholesterol saturation index of bile. ${ }^{9}{ }^{15}$

Although it had been previously suggested, our study is the first to examinate gall bladder bile not obtained during cholecystectomy, but by direct aspiration of bile via fine needle puncture under local anaesthetic.

In our study, the presence of cholesterol crystals and the determination of nucleation time in the puncture bile were the best predictors between cholesterol and pigment gall stones and correlated well with computed tomographic analysis. Furthermore, microscopic examination of bile is easier, quicker, and cheaper than biochemical analysis of bile or computed tomography of the gall bladder.

To date, more than 110 patients have undergone puncture without complications in our clinic. Although it is a semi-invasive procedure, fine needle puncture involves less patient stress and compliance is greater than with endoscopic bile aspiration. 
Given sufficient experience in the procedure, the direct aspiration of bile via fine needle puncture is the method of choice. This method alone allows aspiration of bile of sufficient quality for optimal bile analysis, which, in turn, can lead to better patient selection for conservative gall stone treatment.

1 Danzinger G, Hofmann AF, Schoenfield LJ, Thistle JL. Dissolution of cholesterol gallstones by chenodeoxycholic acid. N Engl f Med 1972; 286: 1-4.

2 Allen MJ, Borody TJ, Bugliosi TF, May GR, LaRusso NF Thistle JL. Cholelitholysis using methyl tertiary butyl ether Gastroenterology 1985; 88: 122-5.

3 Sauerbruch T, Delius M, Paumgartner G, et al. Fragmenta tion of gallstones by extracorporal shock waves. $N E n g l f$ Med 1986; 314: 818-22.

4 Podda M,Zuin M, Dioguardi ML, Festorazzi S, Dioguardi N. A combination of chenodeoxycholic acid and ursodeoxycholic acid is more effective than either alone in reducing biliary cholesterol saturation. Hepatology 1982; 2: 334-9.

5 Hickman MS, Sweisinger WH, Bora JD, Kurtin WE. Computertomographic analysis of gallstones. Arch Surg 1986; 121: 289-91

6 Janowitz P, Zöller A, Swobodnik W, Wechsler JG Schumacher KA, Ditschuneit $H$. Computed evaluation of radiolucent gallstones in vivo. Gastrointest Radiol 1990; 15 $58-60$.

7 Holan KR, Holzbach RT, Herrmann RE, Cooperman AM Claffey MJ. Nucleation time: a key factor in the patho- genesis of cholesterol gallstone disease. Gastroenterology 1979; 77: 611-7.

8 Erpecum VKJ, Van Berge-Henegouwen GP, Stoelwinder B Stolk MFJ, Egginck, WF, Govaert WHA. Cholesterol and pigment gallstone disease: comparison of the reliability of three bile tests for differentiation between the two stone types. Scand F Gastroenterol 1988; 23: 948-54.

9 Ramond MJ, Dumont M, Belghiti J, Eringer S. Sensitivity and specificity of microscopic examination of gallbladder bile for gallstone recognition and identification. Gastroenterology 1988; 5: 1339-43.

10 Janowitz P, Swobodnik W, Wechsler JG, Fischer S Ditschuneit H. Dissolution of radiolucent gallstones by drugs and the nucleation time. Dtsch Med Wochenschr 1989; 114: $983-5$.

11 Swobodnik W, Klüppelberg U, Wechsler JG, Volz M, Normandin G, Ditschuneit $H$. Rapid and accurate reversedphase high-performance liquid chromatographic determination of conjugated bile acids in human bile for routine clinical applications. $\mathcal{F}$ Chromatogr 1985; 339: 263-71.

12 Admirand WH, Small DM. The physicochemical basis of cholesterol gallstone formation in man. $\mathcal{F}$ Clin Invest 1968; 47: 1043-52.

13 Carey MC. Critical table for calculating the cholesterol saturation of native bile. $\mathcal{F}$ Lipid Res 1978; 19: 945-55.

14 Swobodnik $W$, Baumgärtel H, Janowitz $P$, Fuchs $S$, Ditschuneit $\mathbf{H}$. Dissolution of calcified gallbladder stones by Ditschuneit $\mathrm{H}$. Dissolution of calcified gallbladder stones by (Letter). Lancet 1988; ii: 216.

15 Ros E, Navarro S, Fernandes I, Reixach M, Ribo JM, Rodes I Utility of biliary microscopy for the prediction of the chemical composition of gallstones and the outcome of dissolution therapy with ursodeoxycholic acid. Gastroenterology 1986; 91: 703-12. 